\title{
固定翼 UAV における遷移飛行の制御系設計*1 \\ Control Architecture for Transition between Level Flight and Hovering of Fixed-Wing UAV
}

\author{
小夈 昌 範*2 .内 山 賢 治*3 \\ Masanori KokUme and Kenji UchiYama
}

Key Words : Fixed-Wing UAV, Transition, Hovering, Dynamic Inversion Method, $H_{\infty}$ Controller

\begin{abstract}
This paper describes the design of novel control system for a fixed-wing Unmanned Aerial Vehicle (UAV) which can transition between level flight and hovering. The control system is constructed by using dynamic inversion method applying to the translational and rotational nonlinear equations of motion of the UAV. In the controller design for the rotational motion, an observer based on Disturbance Accommodating Control (DAC) method is used to estimate nonlinear parameters. Moreover, $H_{\infty}$ controller is employed to have robustness against estimation error and modeling error on its dynamics. In order to verify the validity of the proposed control system, numerical simulation is performed for the UAV.
\end{abstract}

\section{1. は じめに}

有人では困難な危険領域での観測や，農薬散布，監視，探 査などに無人飛行機（UAV）を利用する機会が増えている. このとき用いられるUAV は, 固定翼 UAV と回転翼 UAV の 2 種類に大別される. 固定翼 UAV は迅速な移動が可能 で, かつ回転翼 UAVに比べて燃費が良いことから広範囲 に及ぶミッションが可能である。一方, 回転翼 UAV は固 定翼 UAV と比較すると航続距離は短いものの, ホバリン グ性能を有することから定点観測などが可能である。これ までは，用途によって各UAVを使い分けていたが，緊急 を伴うミッションでは, 移動速度や広範囲/定点での観測な どが要求される場合がある。この要求をすべて満足するた めには, ティルトウィング式の $\mathrm{UAV}^{11}$ のように特殊な方 式を採用する必要がある。しかし，ティルトウィング式の UAV は複雑な構造をしていることから, 製作コストや制御 性, 故障の発生, 信頼性等の面から, 実用化には困難が伴 うと考えられる。

これとは別に，固定翼 UAV をホバリングさせるシステ ム設計の試みが行われている. Myrand-Lapierre ら2)や Frank ら ${ }^{3)}$ は, 水平定常飛行とホバリングの各状態に対し て線形モデルの構築を行い, それに基づいて制御系設計を 行っている。このように遷移飛行の制御系設計では, 運動 モデルや制御ゲインを切り替えているものが多い.しかし, このような制御系では, 水平定常飛行からホバリングへの 遷移飛行時に扔ける非線形運動は全く考慮されて扔らず, シ

\footnotetext{
*1 (C) 2012 日本航空宇宙学会

平成 23 年 12 月 22 日原稿受付

*2 日本大学大学院理工学研究科航空宇宙工学専攻

*3 日本大学理工学部航空宇宙工学科
}

ステムの安定性に不安が残る。また, Kubo ら4) や松本ら5) はテールシッタ VTOL 機を対象とし，このような問題に取 り組んでいる。しかし前者では機体の横・方向の運動を考 慮しておらず，また後者では機体の並進運動に対する制御 を行っていないため, システムの適用範囲は限られている.

そこで本稿では, 遷移飛行する固定翼UAVに掠いて, 運 動モデルや制御システムの切り替えを必要としない制御系 設計の手法を提案する。本手法では，まず，非線形方程式 で表された UAV の運動モデルに対してダイナミックイン バージョンを適用し, 並進・回転運動の各方程式を線形化 する。 その後，所望の応答が得られるように制御ゲインを 決定する。ただし，UAVの姿勢制御については，モデル化 誤差や空気力項を含む非線形項をJohnson ${ }^{6)}$ によって提案 された DAC オブザーバ (DAC method を推定機構に適用 したもの）によって推定する，また，推定誤差が UAVの 運動に与える影響については, $H_{\infty}$ 制御器の適用により最 小限に抑える. 最後に, 数值シミュレーションにより提案 する手法の有効性を検証する.

\section{2. 運動 モ デル}

2.1 姿勢角表現 UAV の状態量と制御入力を，それぞ れ第 1 図の上うに定義する。慣性座標系は地球表面に固定 し, 機体固定座標系の原点は機体の重心に一致させる.

図中の $U, V, W$ は各々 $x_{B}, y_{B}, z_{B}$ 軸方向の $\mathrm{UAV}$ の 速度を, $P, Q, R$ は各軸周りの $\mathrm{UAV}$ の角速度を表す。機 体の姿勢はエルロン, エレベータ, ラダーの 3 舵によって 制御されるものとし， $\delta_{a} ， \delta_{e}, \delta_{r}$ はそれぞれの舵角を表す。 また，機首にはプロペラを取り付け，それにより発生する 推力 $T$ も操作量の一つとする.

一般に, 航空機の姿勢角表現にはオイラー角が用いられ 

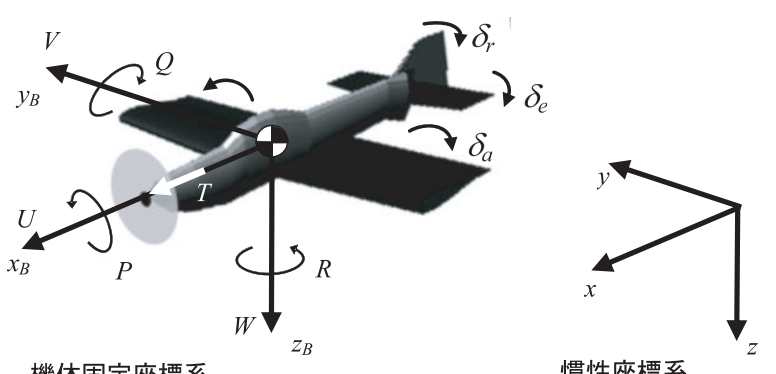

第 1 図 座標系と各変数の定義

る.しかし，本研究で取り扱う遷移飛行問題のように，機 体の姿勢角が $90[\mathrm{deg}]$ を超えるような場合は, 特異点を有 するオイラー角では機体の姿勢を表現することはできない. そこで, UAVの姿勢角表現には, 特異点のないクォータニ オンを用いる．クォータニオンは，物体の瞬時の回転方向 を表わす単位べクトル $\boldsymbol{\lambda}$ と, その回転角度 $\theta$ を用いて以下 のように定義される7)。

$$
\begin{aligned}
& \boldsymbol{q}=\left[\begin{array}{c}
\boldsymbol{\lambda} \sin (\theta / 2) \\
\cos (\theta / 2)
\end{array}\right]=\left[\begin{array}{c}
\overline{\boldsymbol{q}} \\
q_{4}
\end{array}\right]=\left[\begin{array}{llll}
q_{1} & q_{2} & q_{3} & q_{4}
\end{array}\right]^{\mathrm{T}} \\
& \|\boldsymbol{q}\|=\sqrt{q_{1}^{2}+q_{2}^{2}+q_{3}^{2}+q_{4}^{2}}=1
\end{aligned}
$$

クォータニオンによるキネマティクス表現は以下のよう に表される。

$$
\dot{\overline{\boldsymbol{q}}}=\frac{1}{2} \overline{\boldsymbol{E}}(\boldsymbol{q}) \boldsymbol{\omega}, \quad \overline{\boldsymbol{E}}(\boldsymbol{q})=\left[\begin{array}{ccc}
q_{4} & -q_{3} & q_{2} \\
q_{3} & q_{4} & -q_{1} \\
-q_{2} & q_{1} & q_{4}
\end{array}\right]
$$

ここで, $\boldsymbol{\omega}=[P Q R]^{\mathrm{T}}$ は機体の角速度べクトルである。ま た, 慣性座標系から機体固定座標系への座標変換行列 $C^{B / I}$

は, クォータニオンを用いて次式のように表せる.

$$
\boldsymbol{C}^{B / I}=\left[\begin{array}{cc}
q_{1}^{2}-q_{2}^{2}-q_{3}^{2}+q_{4}^{2} & 2\left(q_{1} q_{2}+q_{3} q_{4}\right) \\
2\left(q_{1} q_{2}-q_{3} q_{4}\right) & q_{2}^{2}-q_{3}^{2}-q_{1}^{2}+q_{4}^{2} \\
2\left(q_{3} q_{1}+q_{2} q_{4}\right) & 2\left(q_{2} q_{3}-q_{1} q_{4}\right) \\
2\left(q_{3} q_{1}-q_{2} q_{4}\right) \\
2\left(q_{2} q_{3}+q_{1} q_{4}\right) \\
q_{3}^{2}-q_{1}^{2}-q_{2}^{2}+q_{4}^{2}
\end{array}\right]
$$

2.2 運動方程式 本稿では, UAVの運動方程式として 以下に示すような並進・回転運動に関する非線形方程式を 考える8).

$$
\begin{aligned}
& \dot{\boldsymbol{V}}=-\tilde{\boldsymbol{\omega}} \boldsymbol{V}+\boldsymbol{C}^{B / I} \boldsymbol{g}+\frac{1}{m}\{\boldsymbol{C}(\alpha) \boldsymbol{F}+\boldsymbol{T}\} \\
& \dot{\boldsymbol{\omega}}=-\boldsymbol{J}^{-1} \tilde{\boldsymbol{\omega}} \boldsymbol{J} \boldsymbol{\omega}+\boldsymbol{J}^{-1} \boldsymbol{M}+\boldsymbol{J}^{-1} \boldsymbol{M}_{u} \boldsymbol{u}
\end{aligned}
$$

また，式中の各行列を以下のように定義する.

$$
\begin{aligned}
& \boldsymbol{V}=\left[\begin{array}{lll}
U & V & W
\end{array}\right]^{\mathrm{T}}, \quad \boldsymbol{\omega}=\left[\begin{array}{lll}
P & Q & R
\end{array}\right]^{\mathrm{T}} \\
& \tilde{\boldsymbol{\omega}}=\left[\begin{array}{ccc}
0 & -R & Q \\
R & 0 & -P \\
-Q & P & 0
\end{array}\right] \\
& \boldsymbol{C}(\alpha)=\left[\begin{array}{ccc}
\cos (\alpha) & 0 & -\sin (\alpha) \\
0 & 1 & 0 \\
\sin (\alpha) & 0 & \cos (\alpha)
\end{array}\right] \\
& \boldsymbol{F}=\bar{q} S\left[\begin{array}{c}
-C_{D}(\alpha) \\
C_{y}(\beta)+C_{y_{R}} R+C_{y \delta_{r}} \delta_{r} \\
-C_{L}(\alpha)-C_{L \delta_{e}} \delta_{e}
\end{array}\right] \\
& \boldsymbol{J}=\left[\begin{array}{ccc}
I_{x x} & 0 & -I_{x z} \\
0 & I_{y y} & 0 \\
-I_{x z} & 0 & I_{z z}
\end{array}\right] \\
& \boldsymbol{g}=\left[\begin{array}{lll}
0 & 0 & g
\end{array}\right]^{\mathrm{T}}, \quad \boldsymbol{T}=\left[\begin{array}{lll}
T & 0 & 0
\end{array}\right]^{\mathrm{T}} \\
& \boldsymbol{u}=\left[\begin{array}{lll}
\delta_{a} & \delta_{e} & \delta_{r}
\end{array}\right]^{\mathrm{T}} \\
& M=\bar{q} S\left[\begin{array}{c}
b\left\{C_{l}(\beta)+C_{l_{P}} P+C_{l_{R}} R\right\} \\
\bar{c}\left\{C_{m}(\alpha)+C_{m}(\dot{\alpha})+C_{m_{Q}} Q\right\} \\
b\left\{C_{n}(\beta)+C_{n_{P}} P+C_{n_{R}} R\right\}
\end{array}\right] \\
& +\left[\begin{array}{c}
-M_{\text {drag }}-I_{\text {prop }} \dot{\omega}_{\text {prop }} \\
-I_{\text {prop }} \omega_{\text {prop }} R \\
I_{\text {prop }} \omega_{\text {prop }} Q
\end{array}\right] \\
& \boldsymbol{M}_{u}=\bar{q} S\left[\begin{array}{ccc}
b C_{l \delta_{a}} & 0 & b C_{l \delta_{r}} \\
0 & \bar{c} C_{m \delta_{e}} & 0 \\
b C_{n \delta_{a}} & 0 & b C_{n \delta_{r}}
\end{array}\right] \\
& +\bar{q}_{p r o p} S\left[\begin{array}{ccc}
d C_{l \delta_{a}} & 0 & d C_{l \delta_{r}} \\
0 & \bar{c} C_{m \delta_{e}} & 0 \\
d C_{n \delta_{a}} & 0 & d C_{n \delta_{r}}
\end{array}\right]
\end{aligned}
$$

ここで $\alpha, \beta$ はそれぞれ迎角, 横滑り角であり, $g$ は重力 加速度, $m$ は UAVの機体質量, $b$ は主翼スパン, $\bar{c}$ は主翼 空力平均翼弦, $S$ は主翼翼面積, $d$ はプロペラ直径である. $\bar{q}$ は機体の運動によって発生する動圧, $\bar{q}_{p r o p}$ はプロペラ後 流によって発生する動圧を表わす。また $C_{L}(\alpha), C_{D}(\alpha)$, $C_{m}(\alpha)$ は, それぞれ揚力係数, 抗力係数, 縦摇れモーメン 卜係数であり, その他, 各状態量にかかる係数は安定微係 数, 各舵にかかる係数は制御微係数を表している。モーメ ント $M$ について，第 2 項はプロペラの角運動量の変化や ジャイロ効果により発生するモーメントを表わしている. $I_{\text {prop }}, \omega_{\text {prop }}$ は，それぞれプロペラの慣性モーメント, 角 速度である。また， $M_{\text {drag }}$ は，ブレードが回転する際の抗 力によって発生するモーメントである ${ }^{3)}$. 慣性テンソル $\boldsymbol{J}$ については，機体の対称性から $I_{x z}$ を除くすべての慣性乗 積を $0\left[\mathrm{kgm}^{2}\right]$ としている.

\section{3. 制御系設計}

固定翼 UAVによる遷移飛行を達成するため，本稿では 制御系の設計を 3 段階に分けて考える。なお, 非線形性を 有する並進・回転運動のモデルに対してダイナミックイン 
バージョンを適用しモデルを線形化する.

まず，並進運動に対する制御系を構築し，推力 $T$ の制御 入力を計算する. 次に, 求まった推力 $T$ の方向から, 機体 姿勢の指令值であるクォータニオンコマンド $\boldsymbol{q}_{c}$ を算出す る. 最後に回転運動に対する制御系を構築し, UAVの姿勢 がクォータニオンコマンド $\boldsymbol{q}_{c}$ に追従するよう, 制御入力 $\boldsymbol{u}$ を計算する。並進運動に対する制御系にはPD 制御器, 回 転運動に対する制御系には $H_{\infty}$ 制御器を適用する.

3.1 並進運動に対する制御系 まず, 以下に示す位置誤 差 $\boldsymbol{x}_{e}$ を定義する。

$$
\boldsymbol{x}_{e}=\boldsymbol{x}-\boldsymbol{x}_{c}=\left[\begin{array}{lll}
x-x_{c} & y-y_{c} & z-z_{c}
\end{array}\right]^{\mathrm{T}}
$$

$\boldsymbol{x}$ はUAVの現在の位置であり, $\boldsymbol{x}_{c}$ は目標位置を表す定数 ベクトルである。このとき，(7) 式の時間に関する二階微 分を考えると、

$$
\ddot{\boldsymbol{x}}_{e}=\left[\begin{array}{lll}
\ddot{x} & \ddot{y} & \ddot{z}
\end{array}\right]^{\mathrm{T}}=\dot{\boldsymbol{C}}^{I / B} \boldsymbol{V}+\boldsymbol{C}^{I / B} \dot{\boldsymbol{V}}
$$

となる，このとき，右辺第 2 項に (5) 式を代入し, かつ外 力を考慮してUAVの並進運動方程式を導出する.

$$
\begin{aligned}
\ddot{\boldsymbol{x}}_{e}= & \dot{\boldsymbol{C}}^{I / B} \boldsymbol{V}+\boldsymbol{C}^{I / B} \\
& \times\left[-\tilde{\boldsymbol{\omega}} \boldsymbol{V}+\boldsymbol{C}^{B / I} \boldsymbol{g}+\frac{1}{m}\{\boldsymbol{C}(\alpha) \boldsymbol{F}+\boldsymbol{T}\}\right] \\
= & \dot{\boldsymbol{C}}^{I / B} \boldsymbol{V}-\boldsymbol{C}^{I / B} \tilde{\boldsymbol{\omega}} \boldsymbol{V}+\boldsymbol{g} \\
& +\frac{1}{m} \boldsymbol{C}^{I / B} \boldsymbol{C}(\alpha) \boldsymbol{F}+\frac{1}{m} \boldsymbol{C}^{I / B} \boldsymbol{T} \\
= & \dot{\boldsymbol{C}}^{I / B} \boldsymbol{V}-\boldsymbol{C}^{I / B} \tilde{\boldsymbol{\omega}} \boldsymbol{V}+\boldsymbol{g} \\
& +\frac{1}{m} \boldsymbol{C}^{I / B} \boldsymbol{C}(\alpha) \boldsymbol{F}+\frac{1}{m} \boldsymbol{T}^{I / B}
\end{aligned}
$$

$\boldsymbol{T}^{I / B}=\boldsymbol{C}^{I / B} \boldsymbol{T}=\left[\begin{array}{lll}T_{x} & T_{y} & T_{z}\end{array}\right]^{\mathrm{T}}$ は慣性座標系からみた推 カベクトルである，ここで，(9) 式を線形化するためにダ イナミックインバージョンを適用する。すなわち，(10) 式 に示すようにすべての非線形項を打ち消すような推力べク トル $\boldsymbol{T}^{I / B}$ を考える.

$$
\begin{aligned}
\boldsymbol{T}^{I / B}= & m\left\{-\dot{\boldsymbol{C}}^{I / B} \boldsymbol{V}+\boldsymbol{C}^{I / B} \tilde{\boldsymbol{\omega}} \boldsymbol{V}-\boldsymbol{g}\right. \\
& \left.-\frac{1}{m} \boldsymbol{C}^{I / B} \boldsymbol{C}(\alpha) \boldsymbol{F}+\boldsymbol{v}_{x}\right\}
\end{aligned}
$$

$\boldsymbol{v}_{x}$ は線形化されたシステムにおける新たな制御入力で, こ こでは次式の PD 制御器を用いる.

$$
\boldsymbol{v}_{x}=\boldsymbol{k}_{1} \boldsymbol{x}_{e}+\boldsymbol{k}_{2} \dot{\boldsymbol{x}}_{e}
$$

$\boldsymbol{k}_{1}, \boldsymbol{k}_{2}$ は制御ゲインである. 以上から，ミッションを達成 するために必要な推力 $T$ は, (10) 式で示された推力ベク トル $\boldsymbol{T}^{I / B}$ の大きさとして与えられる.

$$
T=\sqrt{T_{x}^{2}+T_{y}^{2}+T_{z}^{2}}
$$

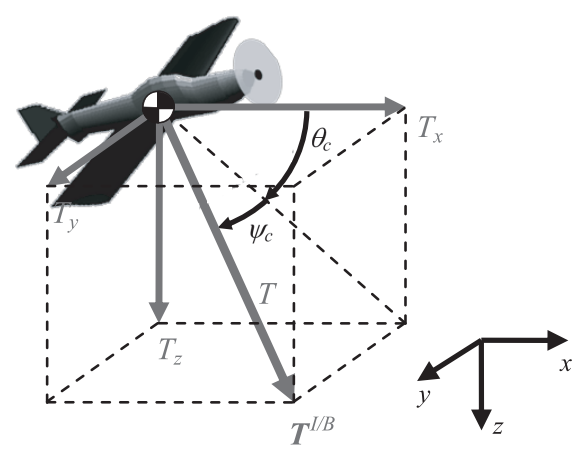

第 2 図 指令角 $\theta_{c} \cdot \psi_{c}$ の生成法

3.2 クォータニオンコマンド 前節では並進運動に対 する制御系を構築し, 推力ベクトル $\boldsymbol{T}^{I / B}$ を算出した。 し かし, 一般的な固定翼 UAV の場合, 推力を発生させるこ とができる方向は図中の $\boldsymbol{x}_{B}$ 軸方向のみである。したがっ て, $\boldsymbol{x}_{B}$ 軸の方向を推力ベクトル $\boldsymbol{T}^{I / B}$ の方向に一致させ る必要がある。そこで第 2 図に示すように, 推力ベクトル $\boldsymbol{T}^{I / B}$ の各軸方向の成分を用いて，ピッチ角，方位角の指 令值 $\theta_{c}, \psi_{c}$ を生成し, 機体の姿勢をこれらに追従させる.

指令角 $\theta_{c}, \psi_{c}$ は推力ベクトル $\boldsymbol{T}^{I / B}$ の各要素を用いて 以下のように求まる。 ロール角については, $\phi_{c}=0[\mathrm{deg}]$ とする。

$$
\begin{aligned}
& \theta_{c}=\tan ^{-1}\left(\frac{T_{z}}{T_{x}}\right) \\
& \psi_{c}=\sin ^{-1}\left(\frac{T_{y}}{T}\right)
\end{aligned}
$$

これらの指令角を各軸周りのクォータニオンに変換する.

$$
\begin{aligned}
\boldsymbol{q}_{\theta} & =\left[\begin{array}{llll}
0 & \sin \left(\frac{\theta_{c}}{2}\right) & 0 & \cos \left(\frac{\theta_{c}}{2}\right)
\end{array}\right]^{\mathrm{T}} \\
\boldsymbol{q}_{\psi} & =\left[\begin{array}{llll}
\sin \left(\theta_{c}\right) & 0 & \cos \left(\theta_{c}\right) \sin \left(\frac{\psi_{c}}{2}\right) & \cos \left(\frac{\psi_{c}}{2}\right)
\end{array}\right]^{\mathrm{T}}
\end{aligned}
$$

(15), (16) 式を用いて，クォータニオンコマンド $\boldsymbol{q}_{c}$ を以 下のように計算する。

$$
\boldsymbol{q}_{c}=\left[\begin{array}{c}
q_{c 1} \\
q_{c 2} \\
q_{c 3} \\
q_{c 4}
\end{array}\right]=\left[\begin{array}{cccc}
q_{\theta 4} & -q_{\theta 3} & q_{\theta 2} & q_{\theta 1} \\
q_{\theta 3} & q_{\theta 4} & -q_{\theta 1} & q_{\theta 2} \\
-q_{\theta 2} & q_{\theta 1} & q_{\theta 4} & q_{\theta 3} \\
-q_{\theta 1} & -q_{\theta 2} & -q_{\theta 3} & q_{\theta 4}
\end{array}\right]\left[\begin{array}{c}
q_{\psi 1} \\
q_{\psi 2} \\
q_{\psi 3} \\
q_{\psi 4}
\end{array}\right]
$$

3.3 回転運動に対する制御系 ここでは, 機体の姿勢 をクォータニオンコマンド $\boldsymbol{q}_{c}$ に素早くかつ正確に追従させ るための制御系を構築する。回転運動に対しても, 並進運 動のときと同様にダイナミックインバージョンを適用する. 前節で述べたように，本機体では，推力の発生方向は第 1 図に示す $x_{B}$ 軸に限られる。このような機体において, 回 転運動に対する制御系が, 機体の安定性や速応性, 収束性 
に与える影響は大きいと考えられる。そこで，回転運動の 制御系を設計する際には，モデル化誤差や空気力項を含む 非線形項を，DACオブザーバによって推定することで制御 性能の劣化を防ぐ6)。この際，過渡期に生じる推定誤差の 影響については $H_{\infty}$ 制御器により改善を図る。

3.3.1 フィードバック線形化 まず，クォータニオンに よるキネマティクスを考える。(3) 式の時間に関する一階 微分を考えると,

$$
\ddot{\ddot{\boldsymbol{q}}}=\frac{1}{2} \dot{\overline{\boldsymbol{E}}}(\boldsymbol{q}) \boldsymbol{\omega}+\frac{1}{2} \overline{\boldsymbol{E}}(\boldsymbol{q}) \dot{\boldsymbol{\omega}}
$$

となる. このとき, 右辺第 2 項に (6) 式を代入することで, (18) 式は UAV の回転運動を考慮したものに書き直すこと ができる.

$$
\begin{aligned}
\ddot{\boldsymbol{q}}= & \frac{1}{2} \dot{\overline{\boldsymbol{E}}}(\boldsymbol{q}) \boldsymbol{\omega}+\frac{1}{2} \overline{\boldsymbol{E}}(\boldsymbol{q}) \\
& \times\left\{-\boldsymbol{J}^{-1} \tilde{\boldsymbol{\omega}} \boldsymbol{J} \boldsymbol{\omega}+\boldsymbol{J}^{-1} \boldsymbol{M}+\boldsymbol{J}^{-1} \boldsymbol{M}_{u} \boldsymbol{u}\right\} \\
= & \frac{1}{2}\left\{\dot{\overline{\boldsymbol{E}}}(\boldsymbol{q}) \boldsymbol{\omega}-\overline{\boldsymbol{E}}(\boldsymbol{q}) \boldsymbol{J}^{-1} \tilde{\boldsymbol{\omega}} \boldsymbol{J} \boldsymbol{\omega}+\overline{\boldsymbol{E}}(\boldsymbol{q}) \boldsymbol{J}^{-1} \boldsymbol{M}\right\} \\
& +\frac{1}{2} \overline{\boldsymbol{E}}(\boldsymbol{q}) \boldsymbol{J}^{-1} \boldsymbol{M}_{u} \boldsymbol{u} \\
= & \boldsymbol{z}_{1}+\boldsymbol{g}_{r} \boldsymbol{u}
\end{aligned}
$$

ここで， $\boldsymbol{z}_{1}$ は推定すべき未知パラメータである，また，本 研究では制御入力に影響するパラメータ $\boldsymbol{g}_{r}$ は既知として 扱う。 DAC オブザーバを設計する際，未知パラメータ $\boldsymbol{z}_{1}$ を (20) 式に示すような時間に関する一次スプライン関数で あると仮定する9 ${ }^{9}$.

$$
z_{1}=c_{1} t+c_{0}, \quad z_{2}=\dot{z}_{1}=c_{1}, \quad z_{3}=\dot{z}_{2}=0
$$

このとき，(19) 式をDAC オブザーバによる推定值を用い た形に書き直すと以下のように表わすことができる.

$$
\ddot{\hat{\boldsymbol{q}}}=\hat{\boldsymbol{z}}_{1}+\boldsymbol{g}_{r} \boldsymbol{u}+\boldsymbol{L}_{1}(\dot{\overline{\boldsymbol{q}}}-\dot{\hat{\boldsymbol{q}}})
$$

ここで， $\boldsymbol{L}_{1}$ はオブザーバゲインであり，式中の“’’は推 定值を示す（20)，(21) 式より，DACオブザーバは以下の ように構成される。

$$
\begin{aligned}
\frac{\mathrm{d}}{\mathrm{d} t}\left[\begin{array}{c}
\dot{\hat{\boldsymbol{q}}} \\
\hat{\boldsymbol{z}}_{1} \\
\hat{\boldsymbol{z}}_{2}
\end{array}\right]= & {\left[\begin{array}{lll}
\mathbf{0}_{3 \times 3} & \boldsymbol{I}_{3 \times 3} & \mathbf{0}_{3 \times 3} \\
\mathbf{0}_{3 \times 3} & \mathbf{0}_{3 \times 3} & \boldsymbol{I}_{3 \times 3} \\
\mathbf{0}_{3 \times 3} & \mathbf{0}_{3 \times 3} & \mathbf{0}_{3 \times 3}
\end{array}\right]\left[\begin{array}{c}
\dot{\hat{\boldsymbol{q}}} \\
\hat{\boldsymbol{z}}_{1} \\
\hat{\boldsymbol{z}}_{2}
\end{array}\right] } \\
& +\left[\begin{array}{c}
\boldsymbol{I}_{3 \times 3} \\
\mathbf{0}_{3 \times 3} \\
\mathbf{0}_{3 \times 3}
\end{array}\right] \boldsymbol{g}_{r} \boldsymbol{u}+\left[\begin{array}{c}
\boldsymbol{L}_{1} \\
\boldsymbol{L}_{2} \\
\boldsymbol{L}_{3}
\end{array}\right](\dot{\overline{\boldsymbol{q}}}-\dot{\hat{\boldsymbol{q}}})
\end{aligned}
$$

DAC オブザーバによって良好に推定が行われたとする と, 各舵の制御入力 $\boldsymbol{u}$ はダイナミックインバージョンを用 いて以下のように計算される。

$$
\boldsymbol{u}=\boldsymbol{g}_{r}^{-1}\left(-\hat{\boldsymbol{z}}_{1}+\boldsymbol{v}_{q}\right)
$$

ここで， $\boldsymbol{v}_{q}$ は，以下に示すような線形化モデルに対する新 しい制御入力と考えることができる。

$$
\frac{\mathrm{d}}{\mathrm{d} t}\left[\begin{array}{c}
\overline{\boldsymbol{q}} \\
\dot{\boldsymbol{q}}
\end{array}\right]=\left[\begin{array}{cc}
\mathbf{0}_{3 \times 3} & \boldsymbol{I}_{3 \times 3} \\
\mathbf{0}_{3 \times 3} & \mathbf{0}_{3 \times 3}
\end{array}\right]\left[\begin{array}{c}
\overline{\boldsymbol{q}} \\
\dot{\boldsymbol{q}}
\end{array}\right]+\left[\begin{array}{c}
\mathbf{0}_{3 \times 3} \\
\boldsymbol{I}_{3 \times 3}
\end{array}\right] \boldsymbol{v}_{q}
$$

3.3.2 $\boldsymbol{H}_{\boldsymbol{\infty}}$ 制御器 運動モデルの不確かさや, 過渡期に おける推定誤差の影響を抑制するために，線形化されたモ デルに対して $H_{\infty}$ 制御器を適用する ${ }^{10)}$. 第 3 図にその概 要を示す.

第 3 図において，破線で囲まれた部分は不確かさを含む 線形化モデルである。図中にあるように，運動モデルの不 確かさ・推定誤差は，一つの不確かさとしてまとめて扱う. 本研究では, この不確かさを入力の乗法的摂動 $\Delta$ として扱 い, $H_{\infty}$ 制御器によってこの摂動の影響を抑制する.

$H_{\infty}$ 制御器を設計する際の一般化プラントを第 4 図に 示す11). 第 4 図に抏いて, $\boldsymbol{W}_{\text {in }}$ は乗法的摂動を表す重み, $\boldsymbol{W}_{\text {act }}$ はアクチュエータの可動範囲を抑える重み, $\boldsymbol{W}_{n}$ は センサノイズを表す重み, $\boldsymbol{W}_{q}$ は機体の姿勢を目標值に追 従させるための重みをそれぞれ示している。 $\boldsymbol{W}_{i n}, \boldsymbol{W}_{n}$ の 重み関数については, 低周波数領域のゲインを下げ, 高周 波外乱の抑制を試みた，逆に，重み関数 $\boldsymbol{W}_{q}$ については高 周波数領域のゲインを下げた。 なお， $\boldsymbol{W}_{\text {act }}$ は制御入力の 最大值によって決まる定数重みである。また， $\boldsymbol{T}_{m}$ は安定

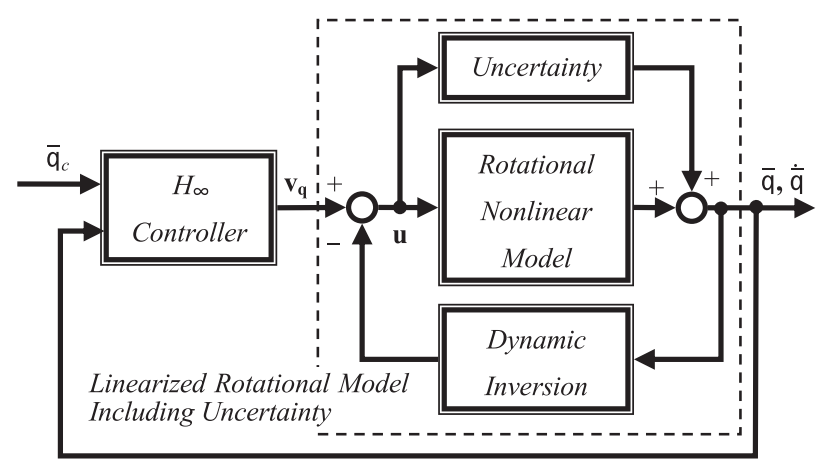

第 3 図回転運動に対する制御系の構成

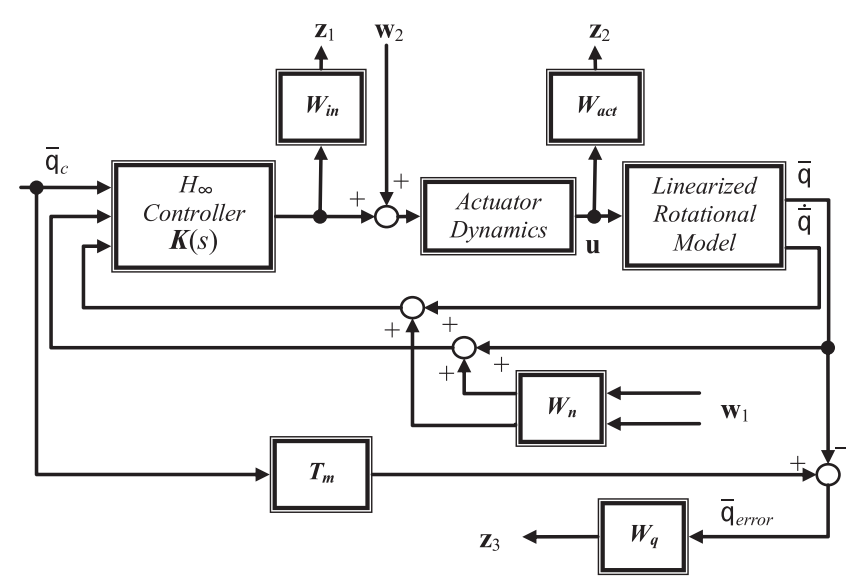

第 4 図 制御対象の一般化プラント 


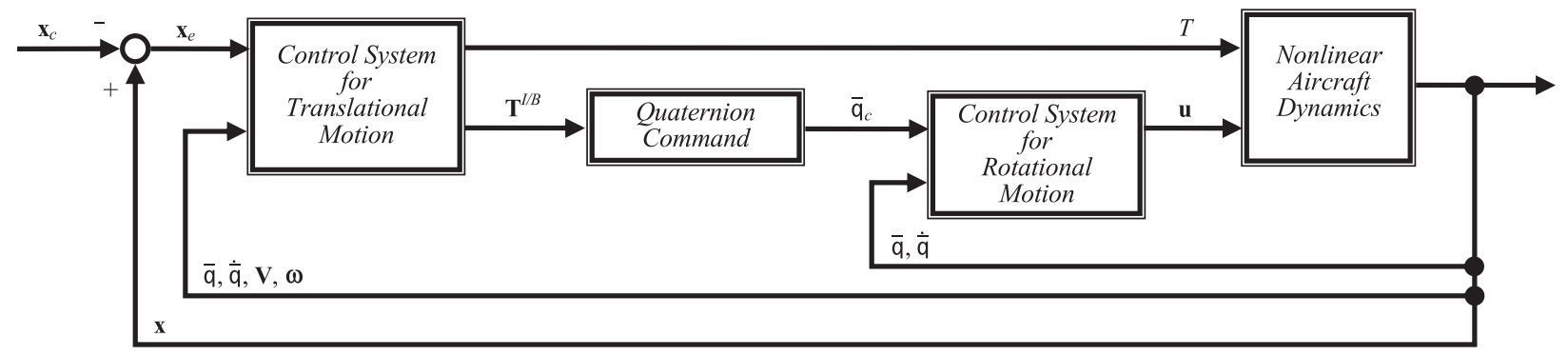

第 5 図＼cjkstart制御系のブロック線図

でプロパーな伝達関数であり, 姿勢を追従させる際の規範 モデルを示している.

第 4 図の一般化プラントに対する $H_{\infty}$ 制御器 $\boldsymbol{K}(s)$ は, 線形行列不等式 (LMI) を用いた方法により求めることが できる12). 以上により, 線形化モデルに対する制御入力 $\boldsymbol{v}_{q}$ は, 求めた $H_{\infty}$ 制御器 $\boldsymbol{K}(s)$ を用いて以下のように表せる.

$$
\boldsymbol{v}_{q}=\boldsymbol{K}(s)\left[\begin{array}{ccc}
\overline{\boldsymbol{q}}_{c}^{\mathrm{T}} & \overline{\boldsymbol{q}}^{\mathrm{T}} & \dot{\overline{\boldsymbol{q}}}^{\mathrm{T}}
\end{array}\right]^{\mathrm{T}}
$$

第 5 図に本章でこれまでに述べた制御系の全体図を示す.

\section{4. 数值シミュレーション}

提案する手法の有効性を数值シミュレーションによって 検証する. 使用する機体の空力係数, 安定微係数, 制御微 係数は, 数值流体解析ソフトの一つである DATCOM を用 いて求めた ${ }^{13)}$ 。また, 慣性モーメント, 慣性乗積は実験に よって求めたものを使用する。第 1 表に本シミュレーショ ンで用いる UAVの機体仕様を示す.

本稿では，第 2 表に示すような二つの制御系に対してシ ミュレーションを行う。システム 1 は，本稿で提案する制 御系で，推定誤差等の影響を考慮している。 システム 2 は 比較対象の制御系で，ロバスト性は考慮していない. PD 制御器の制御ゲインについては, 両システムとも, 振動を 抑制するために実軸上に極を配置した。また，オブザーバ ゲインについては, 線形化モデルの双対性を用い, 最適レ ギュレータ問題を解くことで求めた。

これらの制御系を固定翼 UAVに適用し，2 種類の遷移 飛行に対して数值シミュレーションを行う。まず，ケース 1 として水平定常飛行からホバリングへの遷移飛行を, 次 にケース 2 としてホバリングから水平定常飛行への遷移飛 行を扱った。各々のケースにおけるシミュレーション条件 を第 3 表に示す.

4.1 ケース 1 ここでは, 水平定常飛行からホバリング への遷移飛行のシミュレーション結果を示す.

第 6 図に各UAVの飛行軌跡を示す。両システムともUAV は目標位置に追従している。しかし，システム 2 ではオー バーシュートも見られ，目標位置付近で振動が生じている のに対し，提案する手法（システム 1) ではスムーズな遷 移が達成できている。このことから，システム 1 では $H_{\infty}$ 制御器が良好に機能し, 振動やオーバーシュートを抑制し ていることが分かる。
第 1 表 機体の仕様

\begin{tabular}{ll}
\hline 機体質量 $m[\mathrm{~kg}]$ & 0.37 \\
主翼スパン $b[\mathrm{~m}]$ & 0.9 \\
慣性テンソル $\left(I_{x x}, I_{y y}\right.$, & $(7.80,21.8,27.9,-4.21) 10^{-3}$ \\
$\left.I_{z z}, I_{x z}\right)\left[\mathrm{kgm}^{2}\right]$ & \\
\hline
\end{tabular}

\begin{tabular}{ccc}
\multicolumn{2}{c}{ 第 2 表 } & \multicolumn{3}{c}{ 各シテムで用いる制御器 } \\
\hline 制御器 & 並進運動 & 回転運動 \\
\hline システム 1 & $\mathrm{PD}$ 制御器 & $H_{\infty}$ 制御器 \\
システム 2 & $\mathrm{PD}$ 制御器 & $\mathrm{PD}$ 制御器 \\
\hline
\end{tabular}

第 3 表 シミュレーション条件

\begin{tabular}{lll}
\hline \multicolumn{1}{c}{ 状態量 } & ケース 1 & ケース 2 \\
\hline 初期位置 $\boldsymbol{x}_{0}[\mathrm{~m}]$ & {$\left[\begin{array}{lll}0 & 0 & -5\end{array}\right]^{\mathrm{T}}$} & {$\left[\begin{array}{lll}0 & 0 & -5\end{array}\right]^{\mathrm{T}}$} \\
初期姿勢 $\boldsymbol{q}_{0}[-]$ & {$\left[\begin{array}{llll}0 & 0 & 0 & 1\end{array}\right]^{\mathrm{T}}$} & {$\left[\begin{array}{llll}0 & 0.707 & 0 & 0.707\end{array}\right]^{\mathrm{T}}$} \\
初期速度 $\boldsymbol{V}_{0}[\mathrm{~m} / \mathrm{s}]$ & {$\left[\begin{array}{llll}10 & 0 & 0\end{array}\right]^{\mathrm{T}}$} & {$\left[\begin{array}{lll}0 & 0 & 0\end{array}\right]^{\mathrm{T}}$} \\
初期角速度 $\boldsymbol{\omega}_{0}[\mathrm{rad} / \mathrm{s}]$ & {$\left[\begin{array}{lll}0 & 0 & 0\end{array}\right]^{\mathrm{T}}$} & {$\left[\begin{array}{lll}0 & 0 & 0\end{array}\right]^{\mathrm{T}}$} \\
目標位置 $\boldsymbol{x}_{c}[\mathrm{~m}]$ & {$\left[\begin{array}{llll}15 & 0 & 30 & -50\end{array}\right]^{\mathrm{T}}$} & {$\left[\begin{array}{llll}15 & 5 & 30 & -50\end{array}\right]^{\mathrm{T}}$} \\
\hline
\end{tabular}

第 7,8図に，それぞれのシステムにおけるUAV の状態 量・制御入力の時間履歴を示す. これらの結果を比較して も，システム 1 では各パラメータの振動を抑制できている ことが分かる. 特にクォータニオン $\boldsymbol{q}$ の時間応答において, システム 1 では 40 秒ほどで収束しており, システム 2 と 比較すると速応性についても優れていることが分かる。

両システムの制御入力の時間応答を，第 7 図 $(\mathrm{d}),(\mathrm{e})$ と 第 8 図 (d), (e) にそれぞれ示す。本シミュレーションで用 いた操作量の制約については，実機で実現することを想定 し, $-30 \leq \delta_{a}, \delta_{e}, \delta_{r} \leq 30[\mathrm{deg}], 0 \leq \delta_{t} \leq 9.5[\mathrm{~N}]$ とし た。 今回選定した制御ゲインにおいて, 両システムともす べての制御入力がこれらの範囲に収まっていることが確認 できる。

4.2 ケース 2 このケースでは, ホバリングから定常飛 行への遷移飛行を取り扱う。

第 9 図に，このときの飛行軌跡を示す。システム 2 の飛 行軌跡を見ると, 遷移後の定常飛行において横・方向運動で 振動が生じている。この問題を回避する方法の一つとして, ホバリングと定常飛行の両状態に対する制御系の設計2,3) が挙げられるものの, 状態遷移中の安定性が保証されてい ない等の問題がある。これに対しシステム 1 では, ケース 1 と同様にスムーズに状態が遷移しており, 安定した飛行 が実現されている.

第 10，11 図は，各システムにおける UAV の状態量・制 


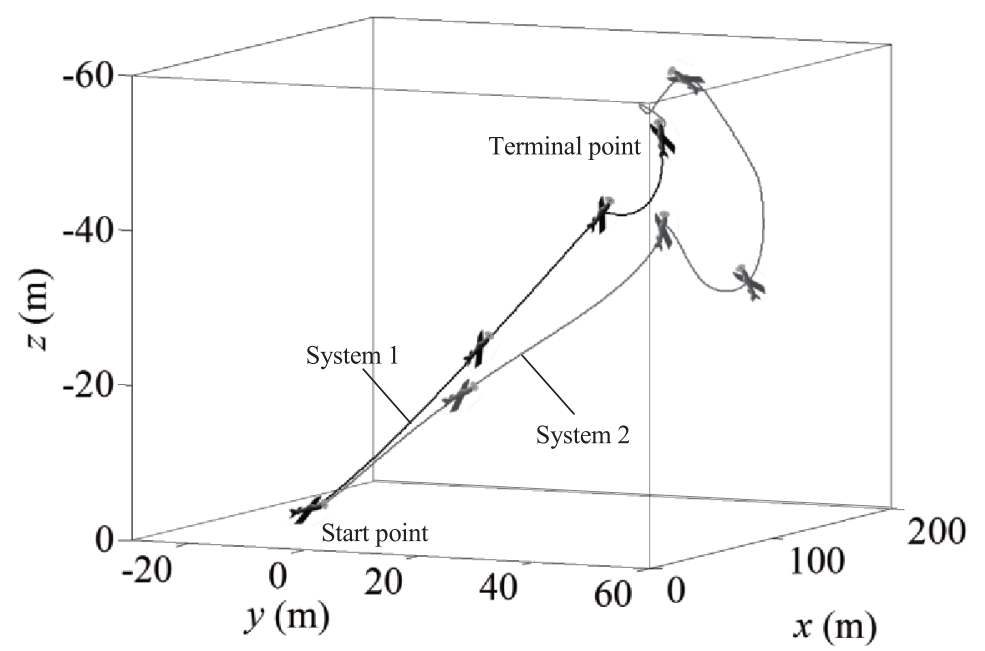

第 6 図 定常飛行からホバリングに遷移する際の飛行軌跡（ケース 1)

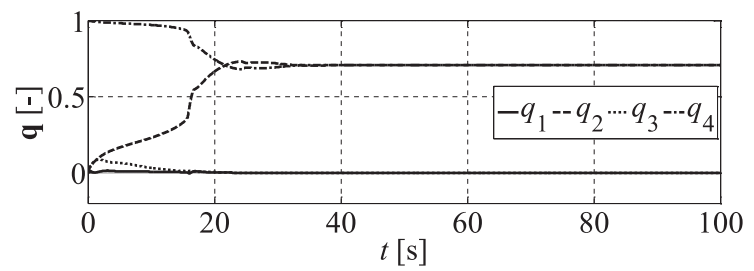

(a) クォータニオン $\boldsymbol{q}$ の時間履歴

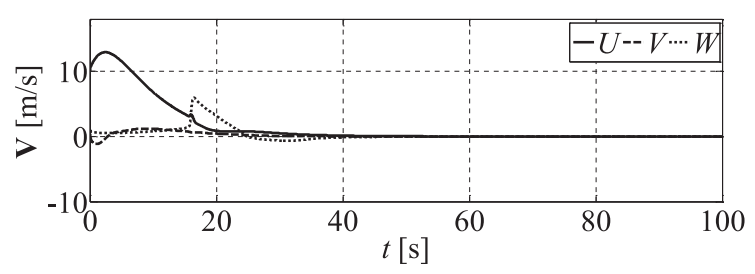

(b) 速度 $\boldsymbol{V}$ の時間履歴

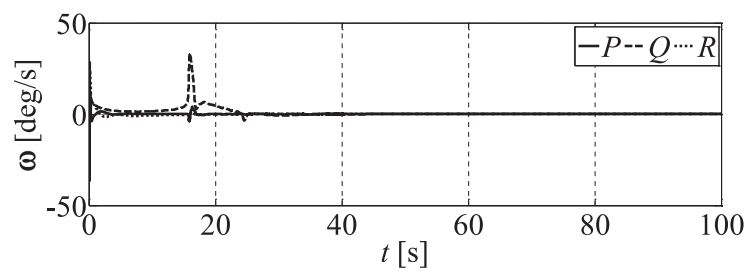

(c) 角速度 $\boldsymbol{\omega}$ の時間履歴

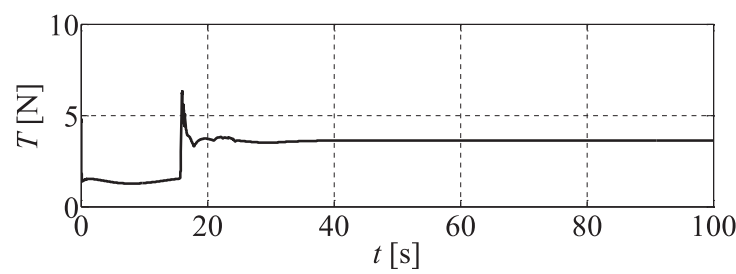

(d) 推力 $T$ の時間履歴

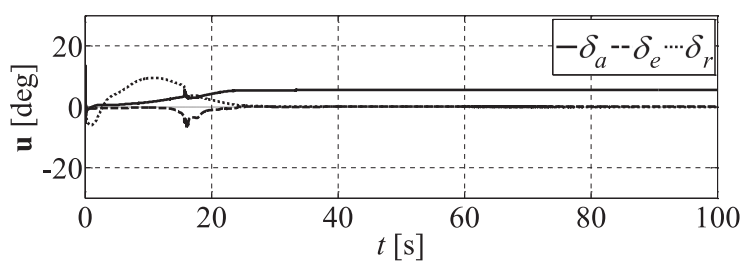

(e) 制御入力 $\boldsymbol{u}$ の時間履歴

第 7 図 システム 1 に扔ける各状態量・制御入力の時間応答 (ケース 1)

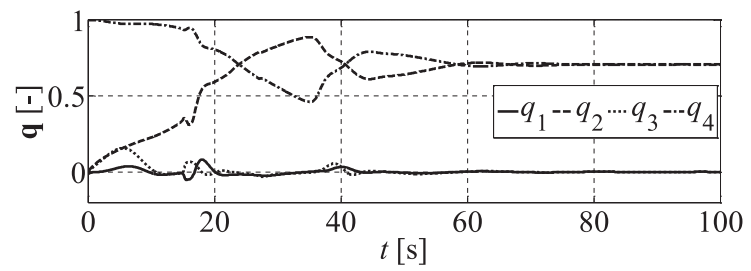

(a) クォータニオン $\boldsymbol{q}$ の時間履歴

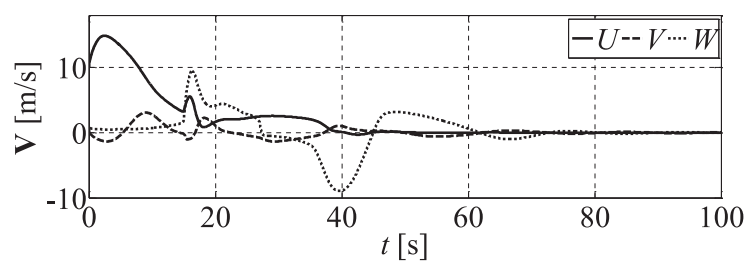

(b) 速度 $\boldsymbol{V}$ の時間履歴

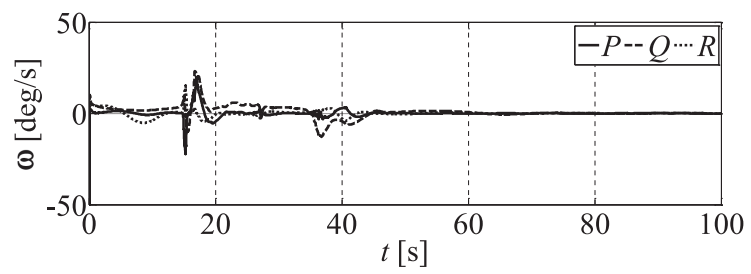

(c) 角速度 $\boldsymbol{\omega}$ の時間履歴

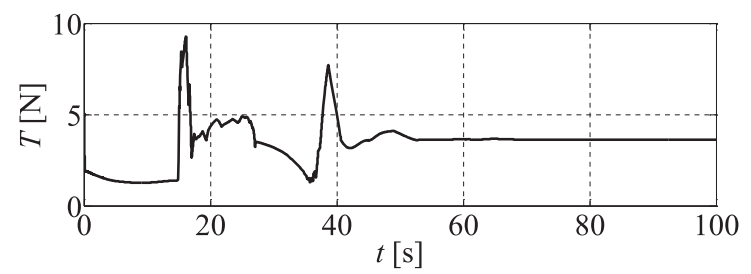

(d) 推力 $T$ の時間履歴

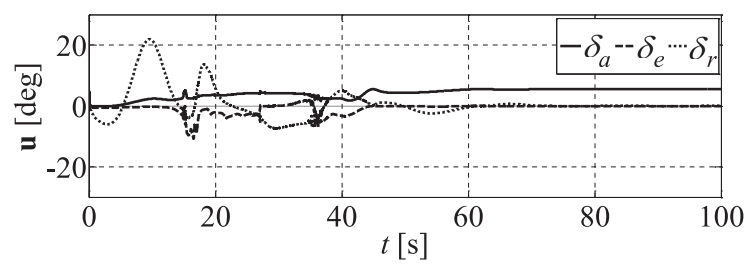

(e) 制御入力 $\boldsymbol{u}$ の時間履歴

第 8 図 システム 2 における各状態量・制御入力の時間応答 (ケース 1) 


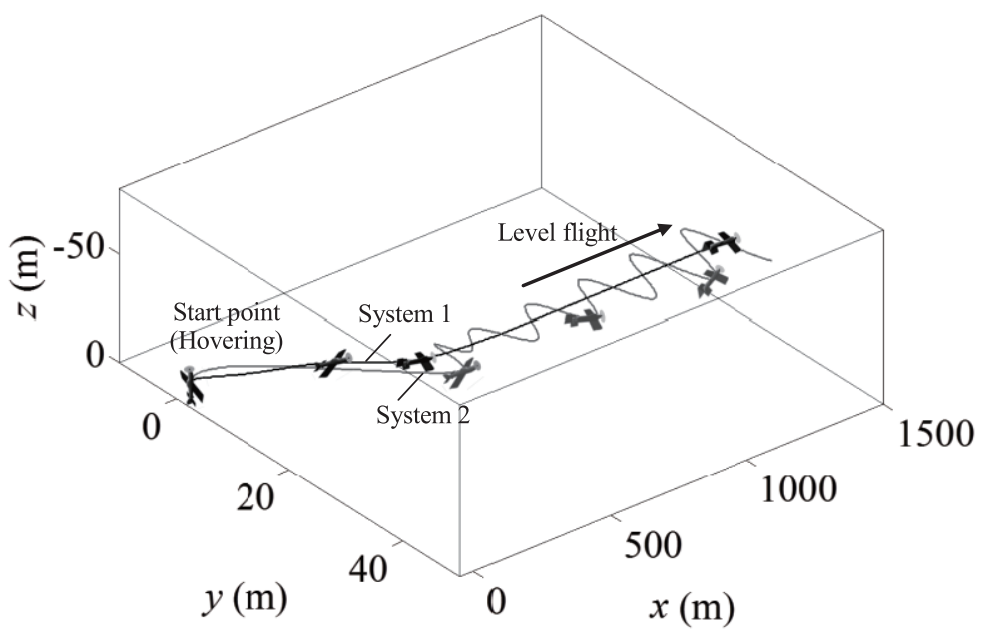

第 9 図 ホバリングから定常飛行に遷移する際の飛行軌跡 (ケース 2)

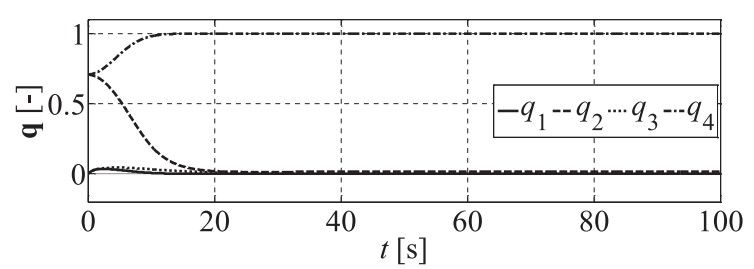

(a) クォータニオン $\boldsymbol{q}$ の時間履歴

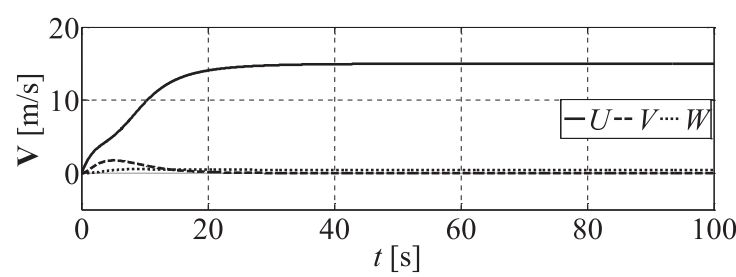

(b) 速度 $\boldsymbol{V}$ の時間履歴

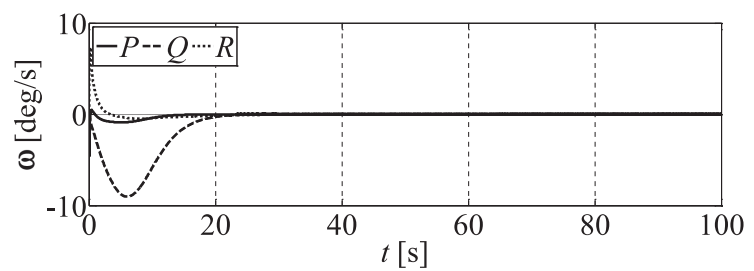

(c) 角速度 $\boldsymbol{\omega}$ の時間履歴

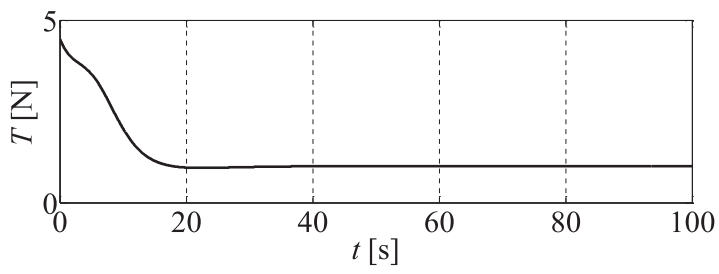

(d) 推力 $T$ の時間履歴

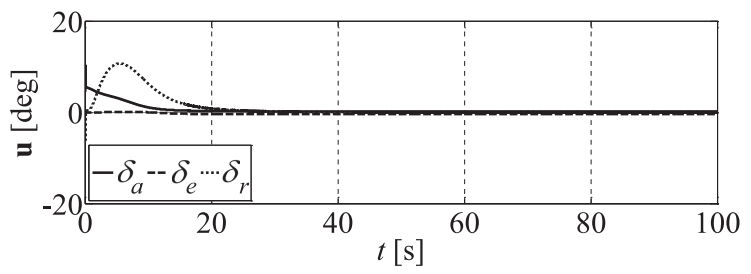

(e) 制御入力 $\boldsymbol{u}$ の時間履歴

第 10 図 システム 1 に扔ける各状態量・制御入力の時間応答 (ケース 2)

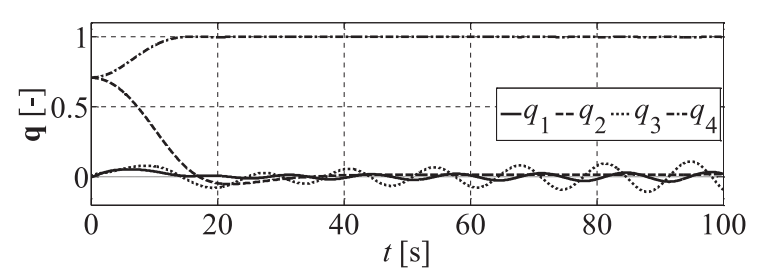

(a) クォータニオン $\boldsymbol{q}$ の時間履歴

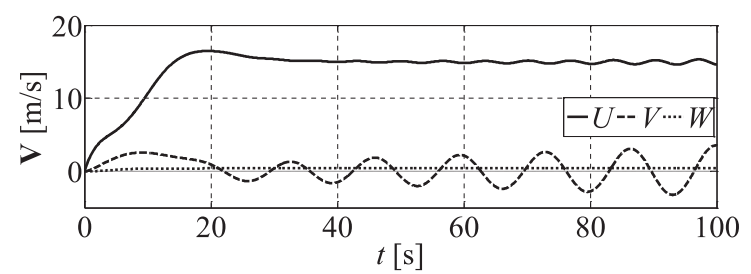

(b) 速度 $\boldsymbol{V}$ の時間履歴

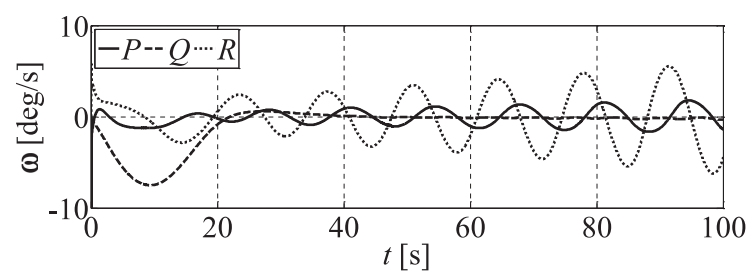

(c) 角速度 $\boldsymbol{\omega}$ の時間履歴

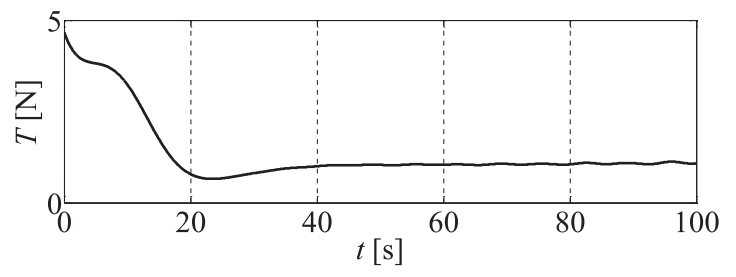

(d) 推力 $T$ の時間履歴

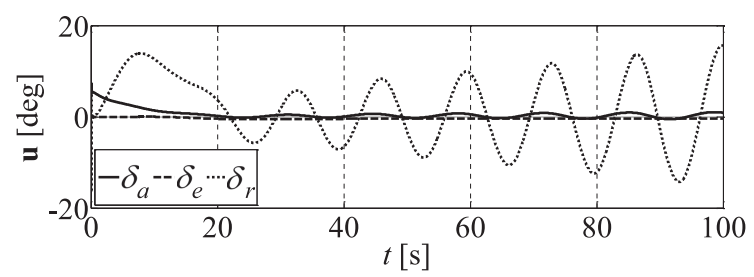

(e) 制御入力 $\boldsymbol{u}$ の時間履歴

第 11 図 システム 2 における各状態量・制御入力の時間応答 (ケース 2$)$ 
御入力の時間履歴である. ケース 1 と同様, ホバリングか ら定常飛行への遷移の際も, $H_{\infty}$ 制御器が良好に機能し, 各パラメータの振動が抑制されている.

第 10 図 (d), (e) と第 11 図 (d), (e) に両システムの制 御入力の時間応答を示す. 本ケースの遷移飛行においても, すべての操作量が可動範囲内に収まっていることが分かる.

\section{5. を と め}

固定翼 UAVによる遷移飛行において，ダイナミクスの 切り替えや制御ゲインの切り替えを行わない新しい制御手 法を提案した。非線形運動方程式で表されたシステムに対 して，ダイナミックインバージョンやDAC オブザーバを 適用し，実機への搭載可能性も配慮した。 UAVの姿勢制 御については, 遷移飛行中に扮ける速応性や振動抑制の改 善を目的として $H_{\infty}$ 制御器を適用した。 最後に, 提案した 手法の有効性を数值シミュレーションにより確認した. 今 後は，実機による実証実験を通して本手法の有効性を確認 する。

本研究の一部は, 科学研究費補助金基盤研究 $(\mathrm{C})$ (21560822) の助成を受けたものである.

\section{参 考 文 献}

1) Muraoka, K., Okada, N. and Kubo, D.: Quad Tilt Wing VTOL UAV: Aerodynamic Characteristics and Prototype Flight Test, AIAA, Unmanned... Unlimited Conference, AIAA Paper 2009-1834, 2009.

2) Myrand-Lapierre, V., Desbiens, A., Gagnon, E., Wong, F. and Poulin, E.: Transitions between Level Flight and Hovering for a Fixed-Wing Mini Aerial Vehicle, Proceedings of the
American Control Conference, 2010, pp. 530-535.

3) Frank, A., McGrew, J. S., Valenti, M., Levine, D. and How, J. P.: Hover, Transition, and Level Flight Control Design for a Single-Propeller Indoor Airplane, AIAA, Guidance, Navigation and Control Conference and Exhibit, AIAA Paper 2007-6318, 2007.

4) Kubo, D. and Suzuki, S.: Tail-Sitter Vertical Takeoff and Landing Unmanned Aerial Vehicle: Transitional Flight Analysis, J. Aircraft, 45 (2008), pp. 292-297.

5) 松本剛明, 近野 敦, 鈴木 兼, 大瀬戸篤司, 吳 健太, 内山 勝: テールシッタ VTOL UAV の最小移動ポストストール姿勢遷移機 動, Proceedings of the 2010 JSME Conference on Robotics and Mechatronics, 2010.

6) Johnson, C. D.: A Family of "Universal Adaptive Controllers" for Linear and Nonlinear Plants, Proceedings of the Twentieth Southeastern Symposium on System Theory, 1988, pp. 530-534.

7) 山口 功, 木田 隆, 岡本 修, 狼 嘉彰: クォータニオンと才 イラー角によるキネマティックス表現の比較について, 航空宇宙 技術研究所資料, NAL TM-636, 1991.

8) Stevens, B. L. and Lewis, F. L.: Aircraft Control and Simulation, Wiley, New York, 1992, Chap. 2.

9) Akai, Y., Shimada, Y., Uchiyama, K. and Abe, A.: Design of Nonlinear Attitude Control System for Spaceplane Using Disturbance-Accommodating Control, Proceedings of KSASJSASS Joint International Symposium on Aerospace Engineering, 2008, pp. 542-547.

10) Sadraey, M. and Colgren, R.: Robust Nonlinear Controller Design for a Complete UAV Mission, Guidance, Navigation and Control Conference, AIAA Paper 2006-6687, 2006.

11) Balas, G. J., Packard, A. K. and M'Closkey, R. T.: Control of the F-14 Aircraft Lateral-Directional Axis during Powered Approach, J. Guid. Control Dynam., 21 (1998), pp. 899-908.

12) Gahinet, P. and Apkarian, P.: A Linear Matrix Inequality Approach to $H_{\infty}$ Control, Int. J. Robust Nonlinear Control, 4 (1994), pp. 421-448.

13) Williams, J. E. and Vukelich, S. R.: The USAF Stability and Control Digital Datcom, Vol. I, User's Manual, McDonnell Douglas Astronautics Company, St. Louis, 1979. 